\title{
REGIONAL ECONOMIC IMPACTS OF NATURAL RESOURCES: THE CASE OF PETROLEUM, AND FORESTRY AND LOGGING IN SARAWĀK
}

\author{
Chakrin Utit \\ Universiti Putra Malaysia \\ M. Yusof Saari* \\ Universiti Putra Malaysia \\ Muhammad Daaniyall Abd Rahman \\ Universiti Putra Malaysia \\ Muzafar Shah Habibullah \\ Putra Business School \\ Umi Zakiah Norazman \\ Universiti Putra Malaysia
}

\begin{abstract}
Extraction of natural resources has created significant contribution to the Malaysian economy as a whole. However, the growth and development of the industry do not necessarily bring considerable economic linkages to the local economy where the industry is located, thus fail to contribute to the welfare of local households. This paper validates this claim by examining the economic impacts of Crude Oil and Natural Gas; Petroleum Refinery; and Forestry and Logging industries on the state of Sarawak. For an empirical analysis, a regional input-output model that developed by using a so-called Simple Location Quotient technique, is used as the main methodology in this study. Results are consistent with our claim that the three industries show significant impacts on growth that measured by value added. However, socio-economic impacts that measured by employment are considerably low. The lower employment impacts can be supported by the two stylized facts. First, the extraction of natural resources is capital-intensive production. The activity requires skilled workers, which might be one of the factors contributing to lower income and job opportunities. Second, the industries are highly dependent on inputs from other states and from abroad, which eventually creates lower economic spill over effects within the state economy.
\end{abstract}

Keywords: Crude oil and natural gas; Petroleum refinery; Forestry and logging; Regional input-output table; Location quotient; Value added; Employment.

Received: 19 May 2018

Accepted: 13 April 2020

\footnotetext{
* Corresponding author: School of Business and Economics, Universiti Putra Malaysia, 43400 UPM Serdang, Selangor, Malaysia, Tel: 03-97697019 and E-mail: mysaari@gmail.com
} 


\section{INTRODUCTION}

Globally, economic value embodied in natural resources makes up a significant proportion of the wealth of most countries, often more than the wealth embodied in produced capital and thus, making natural resources management a key aspect of economic development in developing countries (World Bank, 2006). Natural resources could create wealth directly through tax collection and indirectly through value added of economic activities. For the case of Malaysia, Petroleum (include Crude Oil and Natural Gas, and Refinery), and Forestry and Logging are two main natural resources industries that contribute significantly to the Malaysian economy. The contribution of these industries to the value added is considerable, dominating $12.0 \%$ of the total national value added in 2015 (in 2010 constant prices). Recent evidence shows that the integration of these industries with the remainder of the industries is largely connected through forward linkages compared to backward, implying their imperative role in supporting growth of other industries (Saari, et al., 2016).

This paper attempts to examine the contribution of petroleum, and forestry and logging industries on the local economy by paying specific attention to impacts on the state of Sarawak. We focus our analysis on these two industries in Sarawak because they are found to be the main contributors to the total national production. For example, the latest Economic Census in 2015 indicates that production of Crude Oil and Natural Gas industry in Sarawak contributes 34.3\% to the total production in Malaysia. Production of Forestry and Logging in Sarawak is extremely large, dominating about $67.7 \%$ of total national production. For Sarawak as a whole, these economic industries make the backbone of the state economy, which dominate $49.7 \%$ of total production in the state.

Although extraction of petroleum, and forestry and logging products take place in Sarawak, it is likely that the state does not benefit largely from the growth of these two industries. For example, the average monthly household income for Sarawak in 2016 is RM5,387, positioning itself $22.5 \%$ below the national average (see Economic Planning Unit, 2016). In turn, Sarawak was ranked as the second highest in Malaysia to have poverty incidence rates of $0.6 \%$ in 2016 (see Economic Planning Unit, 2016). These observations are consistent with the literature that shows the natural resources industry does not contribute significantly to the socio-economic development in a region where the industry is located but rather widen up income inequality (see for example, Weber, 2012; Munasib and Rickman, 2015; Gerelmaa and Kotani, 2016).

We argue that the lower impacts of natural resources industries on the socio-economic development of the state can be supported by two stylized facts. First, the extraction of natural resources is capital-intensive production and thus, the neediness of skilled workers might be one of the contributing factors to lower income and job creation. At national level, the contribution of petroleum, and forestry and logging industries to the employment is considerably low with $0.60 \%$ of the share to the total employment in 2015 (see DOSM, 2017a). Second, the industries are highly dependent on inputs from other states and from abroad, and thus create lower economic spill over effects within the state. Saari et al. (2018) shows that lower economic spill over effects explain the lower contribution of petroleum industry to the state of Terengganu. Based on these arguments, this study aims to verify these stylized facts. Among the relevant research questions that the study intends to answer are: (i) how has the development and growth of these industries impacted the 
value added and employment in the state economy?; and (ii) to what extent can the lower regional economic spill over effects be explained by the degree of economic linkages and production intensities of the industries?

The major contribution of this paper to the literature is the development of inter-industry analytical framework at the state economy. It is important to note that examining the economic impacts of natural resources industries on local economies requires an economy-wide model that connects production chains for all industries in a single framework. Thus, the first part of this paper develops a model which is designed to provide a general equilibrium framework for investigating the potential impacts of natural resources industries on the state economy. The data that are necessary to empirically implement such a model are presented in a regional input-output table (RIOT). Using the estimated RIOT, the second part of this paper quantifies the economic impacts through multiplier and linkage measures.

This paper is structured into five sections.

- Section 2 provides our main contribution to the scientific knowledge by reviewing relevant literatures.

- Section 3 presents methodologies for the construction of RIOT for the state of Sarawak.

- $\quad$ Section 4 shows the main findings derived from the multiplier and linkage measures.

- Section 5 provides concluding remarks.

\section{LITERATURE REVIEW}

This section provides important findings from the literature which inform us the research gaps in the area of regional impacts of extraction of natural resources industry. Based on our literature survey, we discovered two main research gaps which provide the novelty aspects of this study. First, we are unable to locate any study in the literature that analyses the economic impacts of extraction of natural resources industry at regional level in general, and at the state of Sarawak specifically. Second, regional studies in Malaysia are highly concentrated on the application of partial equilibrium techniques. As far as the development and industrial planning is concerned, literature shows that an applied general equilibrium analysis such as an input-output model, is widely applied. The following paragraphs detail our literature survey.

A range of empirical studies have been conducted to examine the macroeconomic and environmental impacts of natural resources extraction. The scope of studies ranges from the national economy as a whole, to specific regional and local economies. For the petroleum industry itself, Dutch disease ${ }^{1}$, boom and price shocks are commonly found in the empirical findings from studies around the world, especially for oil-exporting countries (see for example, Dülger et al., 2013; Hasanov, 2013). This includes the study of economic phenomenon known as "resource curse" (see for example, Doraisami, 2015). The dynamic relationship between economic variables concludes that the petroleum industry plays a significant role in the economy.

\footnotetext{
${ }^{1}$ Krugman (1987) defines Dutch disease as the negative impact arise from the discovery of natural resources such as petroleum, which drives a nation currency appreciation through trade activities and thus the crowding out of other tradeable sectors.
} 
In the case of Malaysia, recent studies on petroleum industry include a number of works by Khalid and Liwan (2012), Solaymani et al. (2014), Solarin and Shahbaz (2015) and Saari et al. (2016). These are the national-level studies that emphasize on national crude oil reserve, oil subsidy reforms and natural gas consumption respectively. To the best of our knowledge, impact studies on petroleum industry are concentrated on the national economy and only one study has been found to analyse specifically the regional level (see Saari et al., 2018). Almost all petroleum studies in Malaysia applied econometric models which include the works of Abeysinghe (2001), Park and Yoo (2014) and Badeeb et al. (2016). As a result of these literature gaps, we are able to provide useful insights into the economic impacts of the petroleum industry and linkages at regional or local economies.

For other countries, empirical evidences for the impacts of petroleum industry on its own industry and other industries at the regional level is abundant. These include the works by Papyrakis and Gerlagh (2007), James and Aadland (2011), Weber (2012), Brasier et al. (2014), Haggerty et al. (2014), Maniloff and Mastromonaco (2014), Munasib and Rickman (2015) and Paredes et al. (2015). Among these studies, Papyrakis and Gerlagh (2007) and James and Aadland (2011) reveal a negative link between economic growth and natural resources across regions in the United States. The findings seem to be consistent with that of Paredes et al. (2015) who reported that income spill over effects of natural resources at the regional level is minimal.

In Malaysia, regional studies for other than the petroleum industry have been conducted. For example, Gazi et al. (2014) conduct a survey-based study on economic benefits of artificial reefs in Terengganu. Similar to that, Teh et al. (2011) quantified the socio-economic contribution of small-scale fisheries in Sabah by using an input-output analysis. Also, Jamal et al. (2014) assessed the economic value of health impacts of transboundary smoke haze pollution in Kuala Lumpur and adjacent areas in the state of Selangor, Malaysia.

Similar observations hold for forestry and logging industry. There are number of studies that measure economic impacts of the forestry and logging industry at national levels using econometric and input-output models. For example, descriptive economic analysis linking timber industry in Malaysia with trade and macroeconomic impacts is available (see Malaysian German Chamber of Commerce and Industry, 2010; Zubaidah et al., 2014; Norman, 2016; Umachandran and Sawicka, 2017). Shahwahid (1992) analysed the direct and indirect effects of timber exports on output, value added, employment creation and commodity tax. Rabiul et al. (2010) discussed the scenarios for the impacts of tropical timber-based products on output, value added, income, investment, import, export, final demand and private consumption. To the best of our knowledge, studies on economic impacts of the forestry and logging industry at the state level are not available.

From the methodological point of view, the application of regional input-output model in Malaysia is limited, with the exception of Saari (2014) and Saari et al. (2018). None of the studies used a regional input-output model to examine the impacts of petroleum, and forestry and logging industries on the state of Sarawak. This constitutes another literature gap that this paper aims to contribute to scientific knowledge. 


\section{REGIONAL INPUT-OUTPUT ANALYSIS}

The methodologies used in this section are specifically developed to determine the economic impacts of Forestry and Logging; Crude Oil and Natural Gas; and Petroleum Refinery industries in the state of Sarawak. In particular, input-output model, a technique widely used in the literature of regional studies, has been utilised.

\section{1. $\quad$ Multiplier and linkage measures}

The ability of input-output analysis to capture the whole production interdependencies leads to the wide application of the model for regional analysis (for some basic exposition on input-output analysis, see Miller and Blair, 2009). Literature indicates that most of the applications of the inputoutput model are made at a national level. The interest of extending the application to smaller spatial units such as sub-national regions (i.e. state, district, municipality) have led to some modifications in the national model $^{2}$. There are two specific characteristics referring to the regional dimension which yield evident and necessary distinctions between the national and regional inputoutput models. First, the productive structure of each region in a country is specific, probably being very different from the national one. Second, a small and focused economy makes a region become more dependent on the exterior world (this includes the other regions within the same country and other countries), making exports and imports as important factors in determining the region's demand and supply.

Table 1 illustrates the schematic structure of regional input-output table (RIOT) for Sarawak in the form of a matrix representation. Following to the standard input-output matrix representation in the literature, the $(n \times n)$ matrix $\mathbf{Z}$ denotes the intermediate deliveries and each element of $z_{i j}$ indicates the amount of commodity from sector $i$ used by sector $j$ to produce final goods. Final goods are sold to the ( $n \times k)$ vector of $\mathbf{f}$ that represents final demand consumers - which consists of private consumption (c), investment (i), public consumption $(\mathbf{g})$ and exports $(\mathbf{e})^{3}$. To produce output for final demand consumers, production also requires primary inputs - the $(1 \mathrm{x} n)$ vector $\mathbf{~ m}$ gives the sectoral imports and $(1 \mathrm{x} n)$ vector $\mathbf{v}$ shows the sectoral value added ${ }^{4}$.

\footnotetext{
${ }^{2}$ Technological advancement has also accelerated the development of the regional input-output to be more flexible, cost-effective and transparent (see for example, Lenzen et. al, 2014 and Faturay et. al, 2017).

${ }^{3}$ Final demand for investment includes gross fixed capital formation and change in stock.

${ }^{4}$ Input-output model involves matrix operations. For clarity, matrices are indicated by bold, upright capital letters; vectors by bold, upright lower-case letters and scalar by italicized lower case letters. Vectors are columns by definition, so that row vectors are obtained by transposition, indicated by a prime (e.g. $\mathbf{x}^{\prime}$ ). A diagonal matrix with the elements of vector $\mathrm{x}$ on its main diagonal and all other entries equal to zero are indicated by a circumflex (e.g. $\hat{\mathbf{x}}$ ). A summation vector is represented by $\mathbf{i}$.
} 
Table 1: Simplified Structure of RIOT for Sarawak

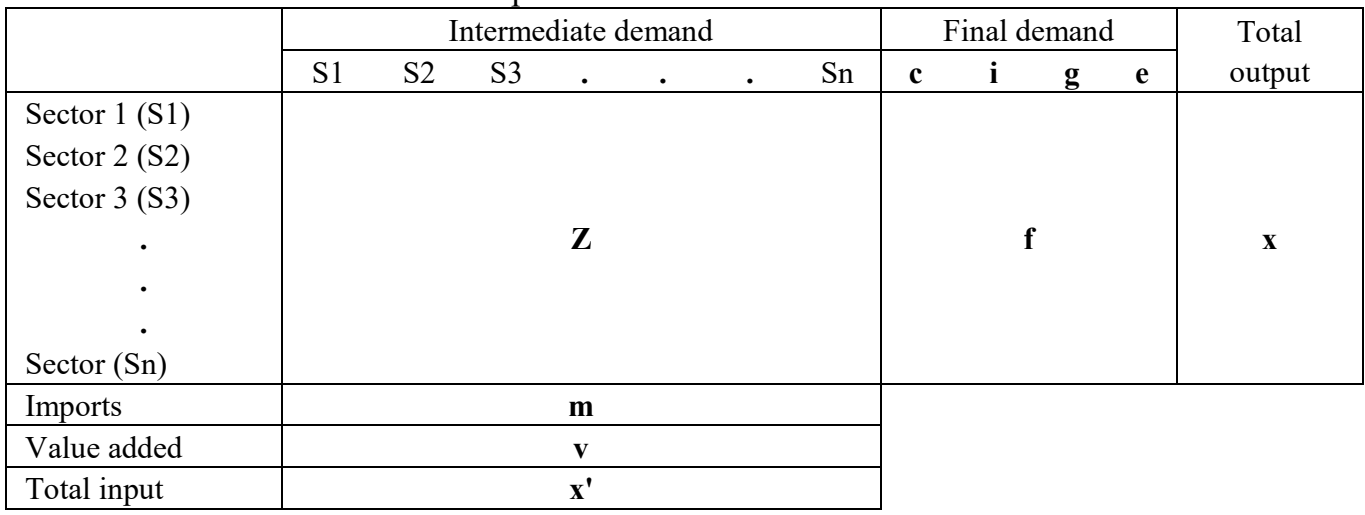

Based on the structure of Table 1, the independencies among production activities can be shown based on the following material-balanced equation:

$\mathbf{x}=\mathbf{Z i}+(\mathbf{c}+\mathbf{i}+\mathbf{g}+\mathbf{e})=\mathbf{Z i}+\mathbf{f}$

where $\mathbf{X}$ is the vector for gross output, $\mathbf{Z i}$ is the summation vector of matrix intermediate deliveries and $\mathbf{f}$ is the vector of final demand. Equation (1) simply shows that the total output of sectors is equal to the summation of intermediate deliveries and final demand. Treating the intermediate deliveries as endogenous component and final demand as exogenous component, (1) can be transformed into a standard input-output model as follows:

$\mathbf{x}=\mathbf{A x}+(\mathbf{c}+\mathbf{i}+\mathbf{g}+\mathbf{e})=\mathbf{A} \mathbf{x}+\mathbf{f}$

where $\mathbf{A}\left(\mathbf{A}=\mathbf{Z} \hat{\mathbf{x}}^{\mathbf{- 1}}\right)$ is known as the input-output coefficient. The input-output coefficients show the amounts of inputs that a sector purchased from other sectors per unit of its own output. Solving for $\mathbf{x}$, we obtain total production delivered to final demand:

$\mathbf{x}=(\mathbf{I}-\mathbf{A})^{-1} \mathbf{f}$

where $\mathbf{I}$ is the identity matrix, and $(\mathbf{I}-\mathbf{A})^{-1}$ is known as the Leontief inverse matrix. The Leontief inverse matrix represents the total production every sector must generate in order to satisfy its final demand.

For a deeper analysis of economic impacts, we decompose the elements of Leontief inverse matrix into direct and indirect effects. This allows the assessment of economic integration between the targeted sectors and the rest of the sectors. The direct effects occurs when an increase in demand for a sector causes the increase in demand of required intermediate inputs from other sectors. The indirect effects are additional demands for all sectors required to satisfy the additional demand determined by the direct effects. Technically, the direct effects are captured by $\mathbf{A}$ matrix while the indirect effects are measured by simply taking the difference between $\mathbf{A}$ and $(\mathbf{I}-\mathbf{A})^{-1}$ matrices. 
In this study, we estimated the economic impacts of Crude Oil and Natural Gas; Petroleum Refinery; and Forestry and Logging by looking at the impacts on value added and employment. These two macroeconomic indicators are the most commonly used in assessing economic impacts of an industry for regional studies ${ }^{5}$. Now, let us expand the standard input-output model in equation (3) to capture the impacts on value added and employment. Introducing a vector of value added coefficient $\mathbf{h}$, which is derived by dividing the amount of value added $\mathbf{v}$ of the $j$ th sector by total input to that sector $x_{j}$. In matrix notation, $\mathbf{h}$ becomes:

$\mathbf{h}=\mathbf{v} \mathbf{x}^{-1}$

Each element of value added coefficient indicates value added per unit of output produced by each sector. By post-multiplying (4) to (3), we obtain the amount of value added (v) that is used to produce output for final demand components.

$\mathbf{v}=\hat{\mathbf{h}}(\mathbf{I}-\mathbf{A})^{-1} \mathbf{c}+\mathbf{i}+\mathbf{g}+\mathbf{e}=\hat{\mathbf{h}}(\mathbf{I}-\mathbf{A})^{-1} \mathbf{f}$

The similar modelling procedures are used for employment effects. Denoting a vector of employment coefficient $\mathbf{w}$, which is derived by dividing the number of employment $\mathbf{u}$ of the $j$ th sector by total input to that of sector $x_{j}$. In matrix notation, $\mathbf{w}$ can be derived as follows:

$\mathbf{w}=\mathbf{u} \mathbf{x}^{-1}$

It is straightforward that the employment effects can be derived as follows:

$\mathbf{u}=\widehat{\mathbf{w}}(\mathbf{I}-\mathbf{A})^{-1} \mathbf{c}+\mathbf{i}+\mathbf{g}+\mathbf{e}=\widehat{\mathbf{w}}(\mathbf{I}-\mathbf{A})^{-1} \mathbf{f}$

The importance of a sector to an economy is commonly identified based on two measures; linkages and multipliers. Equations (5) and (7) only deal with the multipliers with respect to the value added and employment effects. The multipliers must be used complementarily with the backward and forward linkages. This is because analysis of multiplier only provides information regarding the magnitude or size of the impacts without informing policy makers about the spill over effects or linkages. In other words, the multiplier does not inform how much the rest of the sectors in the economy will receive the economic benefits from the output growth of a sector.

Backward and forward linkages measure the level of dependencies between intermediate input purchases and intermediate input sales for a given sector. Backward linkages are derived from the Leontief inverse matrix while the forward linkages are calculated from the Ghosh inverse matrix (see for example, Lenzen, 2003). They can be represented as follows:

$$
\begin{aligned}
& B_{i}=\left((1 / n) \sum_{i} l_{i j} /\left(1 / n^{2}\right) \sum_{i} \sum_{j} l_{i j}\right) \quad \text { for backward linkages } \\
& F_{i}=\left((1 / n) \sum_{j} b_{i j} /\left(1 / n^{2}\right) \sum_{i} \sum_{j} b_{i j}\right) \quad \text { for forward linkages }
\end{aligned}
$$

\footnotetext{
5 Other important indicators used in policy analysis such as salary and wages, and indirect tax cannot be measured due to unavailability of data at industry level.
} 
where $l_{i j}$ indicates an element of the Leontief inverse matrix and $b_{i j}$ represents an element of the Ghosh inverse matrix. Ghosh model is a supply-driven model, where the value added and imports are the exogenous variables, while the final demand is the endogenous variable. In short, the Ghosh model can be summarized as follows:

$\mathbf{x}^{\prime}=\mathbf{i}^{\prime} \hat{\mathbf{x}} \mathbf{B}+\mathbf{d}^{\prime}=\mathbf{x}^{\prime} \mathbf{B}+\mathbf{d}^{\prime}$

where $\mathbf{i}^{\prime} \hat{\mathbf{x}}=\mathbf{x}^{\prime}, \mathbf{B}\left(\mathbf{B}=\hat{\mathbf{x}}^{-\mathbf{1}} \mathbf{Z}\right)$ represents the output coefficient matrix and $\mathbf{d}^{\prime}$ is the vector of primary inputs (i.e. value added and imports). Each element of the output coefficient matrix shows the delivery $z_{i j}$ of commodity sector $i$ to sector $j$ per unit of the seller's output. The solution for (10) is:

$\mathbf{X}^{\prime}=\mathbf{d}^{\prime}(\mathbf{I}-\mathbf{B})^{-1}=\mathbf{d}^{\prime} \mathbf{G}$

\subsection{Estimation of RIOT and data sources}

This section discusses the estimation procedures for RIOT as indicated in Table 1. There are three most commonly used techniques for the construction of RIOT: 1) survey-based, 2) semi-survey, and 3) non-survey techniques. The survey-based technique is associated to a higher degree of accuracy but with a higher cost and is time-consuming through tedious and laborious compilation of data from a nationally representative survey or census. In contrast, the semi-survey and nonsurvey based techniques are associated to a lower degree of accuracy but offering reliable estimates with the limited data and at a lower cost. Given the limited data availability and cost-effective, this study applies the non-survey approach by adapting the Simple Location Quotient (SLQ). Empirical evidences show that the SLQ provides a good approximation for the estimation of "true" regional input-output table (see for example, Miller and Blair, 2009; Morrissey, 2014).

The rationale for using SLQ is discussed by Richardson (1972), Mayer and Pleeter (1975), Round (1983), Miller and Blair (2009), and Habibullah and Radam (2009). Technically, this technique is used to adjust the national input-output coefficients (i.e. from the $\mathbf{A}^{N}$ matrix) in order to estimate the potential demands to be satisfied at the regional level. Denoting economic flows for the state of Sarawak as $S$ and national economy as $N$, the regional input-output coefficient for Sarawak can be defined as:

$a_{i j}^{S S}=L Q_{i}^{S}\left(a_{i j}^{N}\right)$

where $a_{i j}^{S S}$ is the regional input-output coefficient, $L Q_{i}^{S}$ is the location quotient for demonstrating the importance of sector $i$ in the state economy relative to the national economy, $a_{i j}^{N}$ is the national input-output coefficient.

Output, value added and employment are the indicators commonly used to derive the location quotient. Employment data at regional level are also available and as such, most studies in its literature use it for estimation of RIOT (see for example Crawley et. al., 2013). In this study, however, we use value added data to estimate SLQ because of data availability (when value added is not available, then employment is preferred). 
Let $V_{i}^{T}$ and $V^{T}$ denote value added of sector $i$ and total value added in the state $S$, and $V_{i}^{T} / V^{T}$ is the share of both indicators. Similarly, $V_{i}^{N}$ and $V^{N}$ denote value added of sector $i$ and total value added at national economy, and $V_{i}^{N} / V^{N}$ represents their share. Based on these definitions, SLQ can be derived as follows,

$S L Q_{i}=\left(\frac{V_{i}^{T} / V^{T}}{V_{i}^{N} / V^{N}}\right)$

SLQ measures the ability of regional industry $i$ to supply demands placed upon it by other industries in the region and by regional final demand. If SLQ is greater than one (SLQ > 1), this implies that sector $i$ is more concentrated in Sarawak than the nation, and the regional input-output coefficient is similar to the national input-output coefficient. If SLQ is less than one (SLQ $<1$ ), it is assumed that Sarawak is less able to satisfy demands for its output and the national input-output coefficient has to be multiplied by SLQ for sector $i$ in Sarawak. Altogether, the regional inputoutput coefficient is altered based on the following conditions.

$a_{i j}^{S S}=\left\{\begin{array}{cll}a_{i j}^{N}\left(S L Q_{i}^{S}\right) & \text { if } & S L Q_{i}^{S}<1 \\ a_{i j}^{N} & \text { if } & S L Q_{i}^{S} \geq 1\end{array}\right\}$

There are two main steps involved in the estimation of RIOT. The first step is to compile value added data at sectoral levels for Sarawak and Malaysia as a whole. Based on the data, we calculate SLQ index as in Table 2. Recall that, SLQ quantifies how "concentrated" an industry is in a region compared to a larger geographic area. If the SLQ $<1$, output of the sector is not sufficient to meet the local demand and thus imports are required. While if SLQ $>1$, output of the industry is more than sufficient to meet the local demand and the surplus is exported to other regions. The second step is to aggregate the national input-output table from 124 industries into 12 industries, consistent to the industries in Table 2. Based on the national input-output table, we apply SLQ in Table 2 to estimate the RIOT for the state of Sarawak. Technically, if SLQ $<1$, the national input-output coefficient needs to be adjusted downwards by multiplying it to SLQ. If SLQ > 1, no adjustment is made to the national input-output coefficient. In addition, we are aware that there have been several proposed variants of SLQ in the literature of regional input-output studies. Different techniques may produce different outcomes and, in our case, where "true" regional input-output is not available, comparison of different estimation techniques cannot be performed.

Table 2: Simple Location Quotients (SLQ) for Sarawak

\begin{tabular}{llcc}
\hline \hline \multicolumn{1}{c}{ Industries } & SLQ & Implications \\
\hline 1. & Agriculture & 1.03 & Self-sufficient \\
2. Forestry and Logging & 4.03 & Self-sufficient \\
3. & Crude Oil and Natural Gas & 2.42 & Self-sufficient \\
4. Other mining and Quarrying & 0.92 & Imports \\
5. Petroleum Refinery & 5.99 & Self-sufficient \\
6. Manufacturing & 0.35 & Imports \\
7. & Building and Construction & 0.76 & Imports \\
8. Utilities, Transportation and Storage, Information and Communication & 0.62 & Imports \\
9. & 0.53 & Imports \\
\hline
\end{tabular}




\begin{tabular}{lcc}
\hline \hline \multicolumn{1}{c}{ Industries } & SLQ & Implications \\
\hline 10. Banking and Financial Services & 0.46 & Imports \\
11. Private Services & 1.08 & Self-sufficient \\
12. Government Services & 0.65 & Imports \\
\hline \hline
\end{tabular}

Notes:

$\mathrm{LQ}<1$, output of the sector is not sufficient to meet the local demand and thus imports are required.

$\mathrm{LQ}>1$, output of the sector is more than sufficient to meet the local demand and the surplus is exported to other regions.

In this study, four types of data are being used. First is the utilisation of the latest national inputoutput table in 2010 base-year published by the DOSM (2014). The input-output table consists of 124 sectors classified according to the 2008 Malaysia Standard Industrial Classification (MSIC: DOSM, 2008). The second dataset used is the value added by sectors for Malaysia and Sarawak (DOSM, 2015a and 2017b). The third dataset used is the Economic Census report compiled by DOSM (2017a). Finally is to utilise the Labor Force Survey (DOSM, 2015b) in estimating employment by sectors in Sarawak and Malaysia.

\section{RESULTS AND DISCUSSION}

The main findings obtained from the application of RIOT are divided into two sub-sections. Section 4.1 assesses the impacts on growth by focusing the results on value added multiplier and linkages, and Section 4.2 presents the results for the employment multiplier.

\subsection{Impacts on Economic growth}

Results for the multiplier impacts are summarized in Figure 1 for value added. Value added multiplier measures the economy-wide impacts on value added as a result of an increase in one Ringgit of final demand for a particular industry. For example, every Ringgit increase in final demand of Crude Oil and Natural Gas (Industry 3) generates RM0.90 value added for the entire state economy. 
Figure 1: Value Added Multiplier for Sarawak for every Ringgit of Final Demand

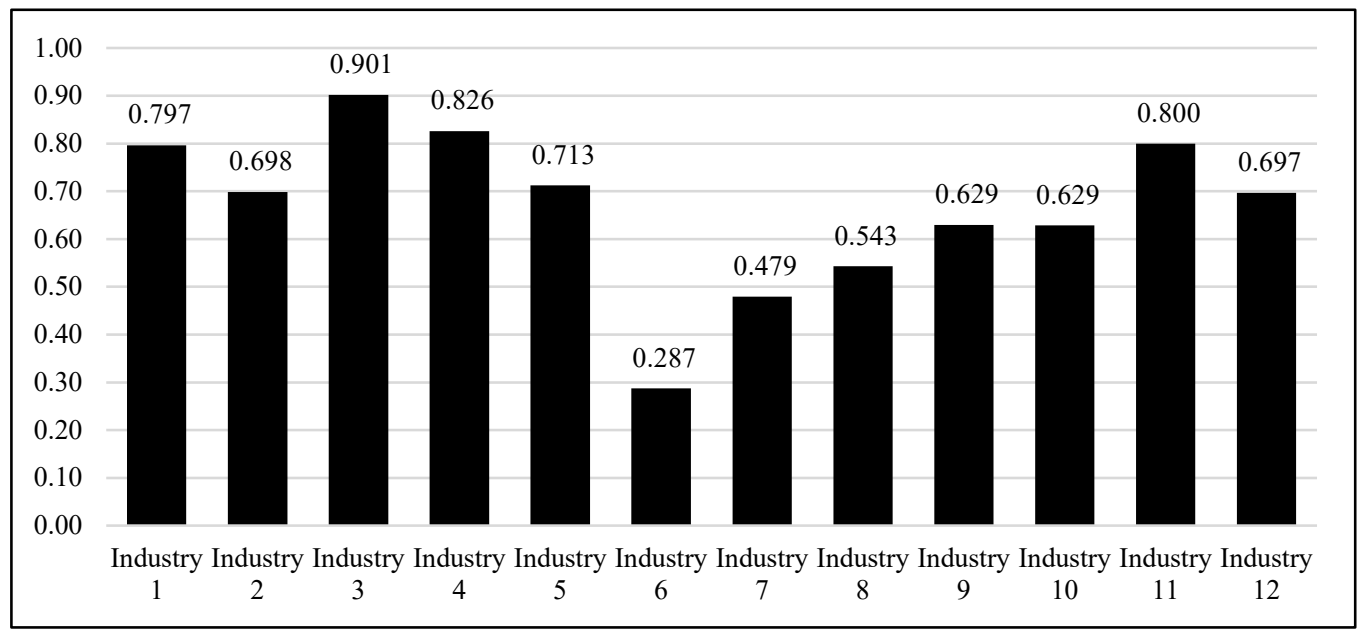

Notes: Industry 1= Agriculture; Industry 2 = Forestry and Logging; Industry $3=$ Crude Oil and Natural Gas; Industry $4=$ Mining and Quarrying; Industry 5 = Petroleum Refinery; Industry $6=$ Manufacturing; Industry $7=$ Building and Construction; Industry $8=$ Utilities, Transportation and Storage, and Information and Communication; Industry $9=$ Wholesale and Retail Trade, Hotels and Restaurants; Industry $10=$ Banking and Financial Services; Industry $11=$ Private Services; and Industry 12 = Government Services.

The results clearly show the importance of Crude Oil and Natural Gas; Petroleum Refinery; and Forestry and Logging industries in promoting growth of the state economy. The Crude Oil and Natural Gas industry is observed to bring the largest economic impacts on Sarawak. Meanwhile, the Petroleum Refinery and Forestry and Logging industries are ranked the fifth and sixth largest contributors towards the value added, respectively. Tables 3,4 and 5 below expand the multipliers by separating the total impacts into the direct and indirect effects, for each of the industries.

Table 3: Direct and Indirect Multiplier Effects for Crude Oil and Natural Gas Industry in Sarawak

\begin{tabular}{llcccccc}
\hline \hline \multirow{2}{*}{\multicolumn{1}{c}{ Industries }} & \multicolumn{3}{c}{ Value Added } & \multicolumn{3}{c}{ Employment } \\
\cline { 2 - 7 } & Total & Direct & Indirect & Total & Direct & Indirect \\
\hline 1. Agriculture & 0.001 & 0.000 & 0.001 & 0.016 & 0.000 & 0.016 \\
2. Forestry and Logging & 0.000 & 0.000 & 0.000 & 0.001 & 0.000 & 0.001 \\
3. Crude Oil and Natural Gas & 0.858 & 0.008 & 0.850 & 0.366 & 0.003 & 0.363 \\
4. Mining and Quarrying & 0.000 & 0.000 & 0.000 & 0.001 & 0.001 & 0.001 \\
5. Petroleum Refinery & 0.006 & 0.005 & 0.000 & 0.002 & 0.002 & 0.000 \\
6. Manufacturing & 0.006 & 0.005 & 0.001 & 0.083 & 0.064 & 0.019 \\
7. Building and Construction & 0.003 & 0.003 & 0.000 & 0.111 & 0.099 & 0.012 \\
8. Utilities, Transportation and Storage, & 0.005 & 0.004 & 0.002 & 0.071 & 0.051 & 0.020 \\
Information and Communication & 0.003 & & & & & \\
9. Wholesale and Retail Trade, Hotels and & 0.008 & 0.006 & 0.002 & 0.164 & 0.127 & 0.037 \\
$\quad$ Restaurants & & & & & &
\end{tabular}




\begin{tabular}{lcccccc}
\hline \hline \multirow{2}{*}{ Industries } & \multicolumn{3}{c}{ Value Added } & \multicolumn{3}{c}{ Employment } \\
\cline { 2 - 7 } & Total & Direct & Indirect & Total & Direct & Indirect \\
\hline 10. Banking and Financial Services & 0.007 & 0.005 & 0.002 & 0.038 & 0.027 & 0.011 \\
11. Private Services & 0.007 & 0.005 & 0.002 & 0.093 & 0.060 & 0.032 \\
12. Government Services & 0.000 & 0.000 & 0.000 & 0.001 & 0.000 & 0.001 \\
\hline Total Multiplier & $\mathbf{0 . 9 0 1}$ & $\mathbf{0 . 0 4 0}$ & $\mathbf{0 . 8 6 1}$ & $\mathbf{0 . 9 4 8}$ & $\mathbf{0 . 4 3 4}$ & $\mathbf{0 . 5 1 4}$ \\
\hline \hline
\end{tabular}

Source: computed from the models

Notes: multiplier for value added is expressed for every one Ringgit increase in final demand while multiplier for employment is expressed for every one million Ringgit increase in final demand.

Table 4: Direct and Indirect Multiplier Effects for Petroleum Refinery Industry in Sarawak

\begin{tabular}{lcccccc}
\hline \multicolumn{1}{c}{ Industries } & \multicolumn{3}{c}{ Value Added } & \multicolumn{3}{c}{ Employment } \\
& Total & Direct & Indirect & Total & Direct & Indirect \\
\hline 1. Agriculture & 0.001 & 0.000 & 0.001 & 0.026 & 0.007 & 0.019 \\
2. Forestry and Logging & 0.000 & 0.000 & 0.000 & 0.001 & 0.000 & 0.001 \\
3. Crude Oil and Natural Gas & 0.435 & 0.422 & 0.013 & 0.186 & 0.180 & 0.006 \\
4. Mining and Quarrying & 0.000 & 0.000 & 0.000 & 0.001 & 0.000 & 0.001 \\
5. Petroleum Refinery & 0.224 & 0.002 & 0.223 & 0.089 & 0.001 & 0.088 \\
6. Manufacturing & 0.006 & 0.002 & 0.004 & 0.077 & 0.024 & 0.053 \\
7. Building and Construction & 0.002 & 0.000 & 0.002 & 0.069 & 0.009 & 0.059 \\
8. Utilities, Transportation and Storage, & 0.007 & 0.003 & 0.004 & 0.096 & 0.046 & 0.051 \\
$\quad$ Information and Communication & & & & & & \\
9. Wholesale and Retail Trade, Hotels & 0.021 & 0.016 & 0.005 & 0.433 & 0.327 & 0.106 \\
$\quad$ and Restaurants & 0.009 & 0.004 & 0.005 & 0.048 & 0.021 & 0.026 \\
10. Banking and Financial Services & 0.007 & 0.002 & 0.005 & 0.091 & 0.022 & 0.069 \\
11. Private Services & 0.000 & 0.000 & 0.000 & 0.001 & 0.000 & 0.001 \\
12. Government Services & $\mathbf{0 . 7 1 3}$ & $\mathbf{0 . 4 5 1}$ & $\mathbf{0 . 2 6 2}$ & $\mathbf{1 . 1 1 8}$ & $\mathbf{0 . 6 3 7}$ & $\mathbf{0 . 4 8 1}$ \\
\hline Total Multiplier & & & & & &
\end{tabular}

Source: computed from the models

Notes: multiplier for value added is expressed for every one Ringgit increase in final demand while multiplier for employment is expressed for every one million Ringgit increase in final demand.

Table 5: Direct and Indirect Multiplier Effects for Forestry and Logging Industry in Sarawak

\begin{tabular}{|c|c|c|c|c|c|c|}
\hline \multirow{2}{*}{ Industries } & \multicolumn{3}{|c|}{ Value Added } & \multicolumn{3}{|c|}{ Employment } \\
\hline & Total & Direct & Indirect & Total & Direct & Indirect \\
\hline 1. Agriculture & 0.003 & 0.000 & 0.003 & 0.059 & 0.002 & 0.057 \\
\hline 2. Forestry and Logging & 0.471 & 0.100 & 0.370 & 7.017 & 1.497 & 5.520 \\
\hline 3. Crude Oil and Natural Gas & 0.053 & 0.000 & 0.053 & 0.023 & 0.000 & 0.023 \\
\hline 4. Mining and Quarrying & 0.003 & 0.001 & 0.001 & 0.009 & 0.004 & 0.005 \\
\hline 5. Petroleum Refinery & 0.027 & 0.018 & 0.010 & 0.011 & 0.007 & 0.004 \\
\hline 6. Manufacturing & 0.017 & 0.008 & 0.009 & 0.224 & 0.101 & 0.123 \\
\hline 7. Building and Construction & 0.013 & 0.008 & 0.005 & 0.502 & 0.315 & 0.188 \\
\hline 8. Utilities, Transportation and Storage, & 0.021 & 0.010 & 0.010 & 0.274 & 0.138 & 0.136 \\
\hline
\end{tabular}




\begin{tabular}{lcccccc}
\hline \hline \multirow{2}{*}{\multicolumn{1}{c}{ Industries }} & \multicolumn{3}{c}{ Value Added } & \multicolumn{3}{c}{ Employment } \\
\cline { 2 - 7 } & Total & Direct & Indirect & Total & Direct & Indirect \\
\hline \multicolumn{1}{c}{ Information and Communication } & & & & & & \\
\hline $\begin{array}{l}\text { 9. Wholesale and Retail Trade, Hotels } \\
\text { and Restaurants }\end{array}$ & 0.058 & 0.035 & 0.023 & 1.210 & 0.731 & 0.480 \\
10. Banking and Financial Services & 0.005 & 0.000 & 0.005 & 0.026 & 0.000 & 0.026 \\
11. Private Services & 0.027 & 0.012 & 0.015 & 0.357 & 0.160 & 0.197 \\
12. Government Services & 0.000 & 0.000 & 0.000 & 0.001 & 0.000 & 0.001 \\
\hline Total Multiplier & $\mathbf{0 . 6 9 8}$ & $\mathbf{0 . 1 9 3}$ & $\mathbf{0 . 5 0 5}$ & $\mathbf{9 . 7 1 4}$ & $\mathbf{2 . 9 5 5}$ & $\mathbf{6 . 7 5 9}$ \\
\hline \hline
\end{tabular}

Source: computed from the models

Notes: multiplier for value added is expressed for every one Ringgit increase in final demand while multiplier for employment is expressed for every one million Ringgit increase in final demand.

The results in Tables 3,4 and 5 decompose the contribution of the multipliers by specific industries and can be linked to both Figures 1 and 2. Figure 1 indicates that every Ringgit increase in final demand of Crude Oil and Natural Gas industry generates RM0.90 value added for the entire state economy. The first column of Table 3 decomposes these RM0.90 according to industries breakdown. Out of RM0.90, RM0.86 or $95 \%$ is contributed by the industry itself, RM0.008 or $0.9 \%$ is generated by Wholesale and Retail Trade, Hotels and Restaurants industry and so on. Further, the next two columns decompose the total multiplier into the direct and indirect effects. For example, out of RM0.90 total value added generated by the Crude Oil and Natural Gas industry in the entire state economy, $4.4 \%$ or RM0.04 are generated through the direct effects while the remaining $95.6 \%$ or RM0.86 are contributed by the indirect effects.

Comparing the results in Tables 3,4 and 5 clearly provides an indication of differences in the level of economic integration between Crude Oil and Natural Gas; Petroleum Refinery; and Forestry and Logging industries with other industries (as measured by the indirect effects) in Sarawak. Note that, in an economy, circulation does matter-the more integrated the industries are, the more economic circulations occur. Thus, weak industries structural integration explains why the value added multiplier differs across industries.

For Petroleum Refinery industry (see Table 4), the direct effects explain $63.3 \%$ of the multiplier and the remaining $36.7 \%$ are contributed by the indirect effects. On the other hand, the findings for Crude Oil and Natural Gas; and Forestry and Logging industries are different for which the indirect effects dominate the impacts. For Crude Oil and Natural Gas, the indirect effects explain 95.6\% while for Forestry and Logging, the indirect effects contribute $72.3 \%$. This result shows that the Crude Oil and Natural Gas; and Forestry and Logging industries are more integrated with the rest of the sectors in the state economy. This implies that growth in output of these two sectors would also bring benefits to other industries compared to the less integrated sector of Petroleum Refinery.

Recall that the multiplier only provides information regarding the size of the effects without giving information on the extent to which the 'size' can stimulate growth to the other industries. A large multiplier impact does not inform the policy makers whether that industry is passively receiving impulses from other industries or actively sending impulses to the other industries. Thus, additional 
measures that we need are the backward and forward linkages. Table 6 shows the estimated backward and forward linkages in Sarawak.

Table 6: Backward and Forward Linkages for Sarawak

\begin{tabular}{|c|c|c|}
\hline Industries & "Backward & Forward \\
\hline 1. Agriculture & 0.943 & 0.921 \\
\hline 2. Forestry and Logging & 1.421 & 1.292 \\
\hline 3. Crude Oil and Natural Gas & 0.816 & 1.235 \\
\hline 4. Mining and Quarrying & 0.879 & 1.087 \\
\hline 5. Petroleum Refinery & 1.186 & 0.959 \\
\hline 6. Manufacturing & 0.866 & 0.844 \\
\hline 7. Building and Construction & 1.078 & 0.839 \\
\hline 8. Utilities, Transportation and Storage, Information and Communication & 1.013 & 1.031 \\
\hline 9. Wholesale and Retail Trade, Hotels and Restaurants & 0.888 & 0.880 \\
\hline 10. Banking and Financial Services & 0.919 & 1.107 \\
\hline 11. Private Services & 1.084 & 1.090 \\
\hline 12. Government Services & 0.906 & 0.714 \\
\hline
\end{tabular}

Source: computed from the models

Recall that if the values for both forward and backward linkages are greater than one for a particular sector, it implies that the industry plays a significant role in regional economic development by supporting (forward linkages) as well as boosting (backward linkages) the other industries. Based on the results in Table 6, we can observe that the Forestry and Logging industry is considered to be the most important industries to the state of Sarawak, compared to the Petroleum Refinery; and Crude Oil and Natural Gas. Growth of the Forestry and Logging industry possesses large capacity in boosting and supporting other industries.

For Crude Oil and Natural Gas, this sector is not identified as the key sector as it only exhibits high forward linkages. This implies that the industry plays an important role in supporting the growth of other sectors, but less important for backward linkages. On the contrary, the Petroleum Refinery industry is an important industry that helps to pull the growth of other domestic sectors in Sarawak through backward linkages. The low forward linkages for this industry shows that most of the output are exported to the other states in Malaysia.

\subsection{Impacts on employment}

We have shown that Crude Oil and Natural Gas; Petroleum Refinery; and Forestry and Logging are important industries that contribute significantly to the economic growth (measured by value added). Next, we examine the extent to which the growth has benefitted the households by looking at the employment multiplier. Results for the employment multiplier are presented in Figure 2. To be more meaningful, we present the multiplier for every million Ringgit increases in final demand. 
Figure 2: Employment Multiplier for Sarawak for Every Million Ringgit of Final Demand

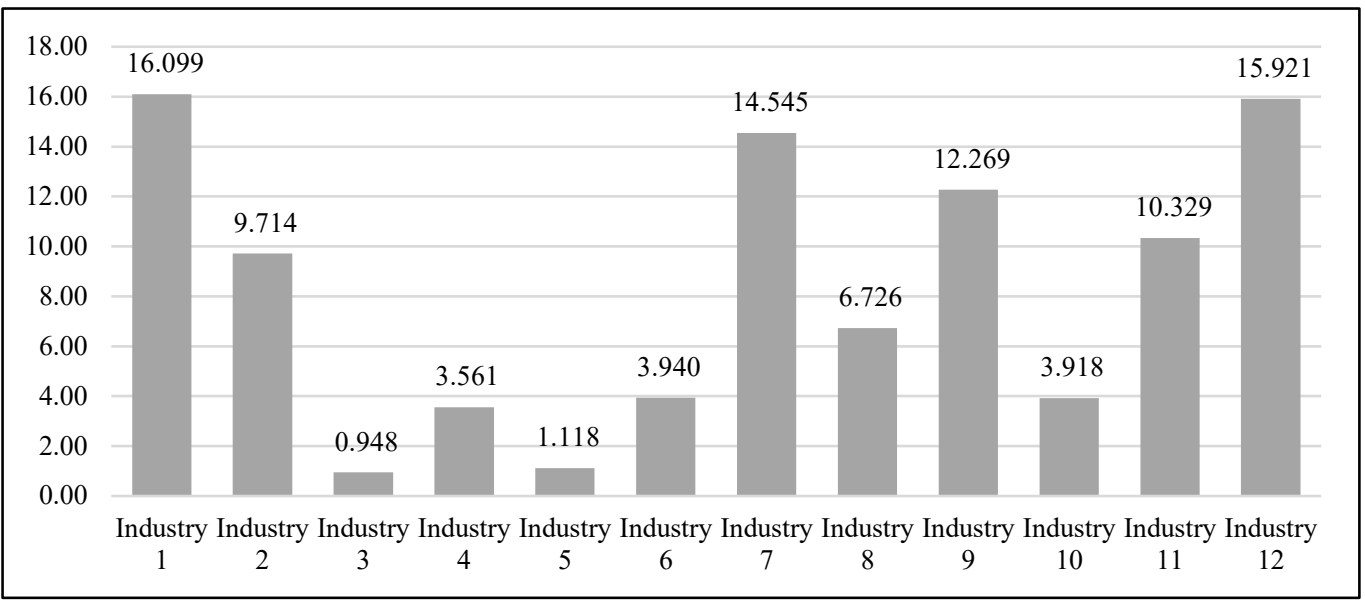

Notes: Industry 1= Agriculture; Industry 2 = Forestry and Logging; Industry 3 = Crude Oil and Natural Gas; Industry $4=$ Mining and Quarrying; Industry 5 = Petroleum Refinery; Industry $6=$ Manufacturing; Industry $7=$ Building and Construction; Industry $8=$ Utilities, Transportation and Storage, and Information and Communication; Industry $9=$ Wholesale and Retail Trade, Hotels and Restaurants; Industry $10=$ Banking and Financial Services; Industry $11=$ Private Services; and Industry 12 = Government Services.

Comparison of results in Figure 1 and Figure 2 clearly indicates that Crude Oil and Natural Gas; Petroleum Refinery; and Forestry and Logging industries contribute more to the economic growth than to employment. This is empirically true as the Crude Oil and Natural Gas industry is found to gain the highest impacts in term of the value added compared to all industries, but the Agriculture industry is observed to generate more jobs. The lower employment multiplier can be explained by the fact that these three industries are essentially capital-intensive. As capital-intensive industries, their productions are more capital dependent and less labour dependent. This finding can be supported by data from the latest Economic Census. For example, the total employment in Agriculture industry makes up $4.79 \%$ of total national while Crude Oil and Natural Gas employment is only $0.48 \%$. Furthermore, the composition of employment in the Crude Oil and Natural Gas are skilled workers with share of $28.61 \%$ of total employments in the industry whereas skilled workers in the Agriculture industry are only $2.25 \%$.

In addition to the capital-intensive perspective, the consumption of imported inputs in the production of each industry is also an element that contributes to the lower employment impacts. It is observed that the import requirement for the Petroleum Refinery output is relatively higher among the three industries amounting to $21.04 \%$ (at national level this sector consumes $27 \%$ of imported inputs observed in the national input-output table). It implies that for every Ringgit of output produced by this industry, it requires RM0.21 of imported inputs. However, despite being the highest value-added sector, the Forestry and Logging industry does not consume a large amount of imported inputs for its production. Instead, the industry commonly uses inland resources such as local forests and runs as an intermediary resource extractor. The extracted resources (i.e. timber) are then sold off to the manufacturing sector for further processing. 
Among the three industries, the Forestry and Logging is considered to be less capital-intensive compared to the Crude Oil and Natural Gas; and Petroleum Refinery. For every million Ringgit increase in final demand, Forestry and Logging generates 10 jobs compared to the Crude Oil and Natural Gas; and Petroleum Refinery that creates only about 1 job, respectively. The results for the decomposition in Tables, 3,4 and 5 are relatively similar to the value added, where the indirect effects are dominant for the Crude Oil and Natural Gas; and Forestry and Logging industry while direct effects are the major forces for the Petroleum Refinery.

\section{CONCLUSION}

This paper documents findings from a study that examines the economic impacts of Crude Oil and Natural Gas; Petroleum Refinery; and Forestry and Logging industries on the state of Sarawak. Altogether, two most important implications are derived from the results. First, natural resources industry at local economy structurally exhibits a low economic integration with other industries. Particularly, the two petroleum-related industries, Crude Oil and Natural Gas, and Petroleum Refinery, are less integrated with the rest of the industries in the economy as measured by the indirect multiplier effects and linkages. Given the importance of industrial linkages for economic development and efforts that focused on how to promote economic diversification of the economy are important. In particular, how to ensure benefits from growth and development of natural resources can be maximized. Importantly, circulation does matter in economy-the more integrated the industries are, the more economic circulations occur.

Second, the natural resources industry does not show considerable contribution to the socioeconomic development in a region where the industry is located. Results show the impacts of growth in the Crude Oil and Natural Gas; Petroleum Refinery; Forestry and Logging industries has less benefitted the households in Sarawak - as indicated by the lower employment multiplier. This observation provides answers to why the average monthly household income in Sarawak is below the national average while providing further explanation to why Sarawak is identified as the second highest state with poverty incidence. Overall, the lower impacts of natural resources industries on the socio-economic development of the state can be supported by two stylized facts: 1) the extraction of natural resources is capital-intensive and thus the neediness of skilled workers might be one of the factors contributing to lower income and job creations, and 2) the industries are highly dependent on inputs from other regions locally and abroad, thus creating lower economic spill over effects within the region.

\section{REFERENCES}

Abeysinghe, T. (2001). Estimation of direct and indirect impact of oil price on growth. Economics Letters, 73(2), 147-153.

Badeeb, R. A., Lean, H. H., \& Smyth, R. (2016). Oil curse and finance-growth nexus in Malaysia: the role of investment. Energy Economics, 57, 154-165. 
Brasier, K., Davis, L., Glenna, L., Kelsey, T., McLaughlin, D., Schafft, K., Babbie, K., Biddle, C., Delessio-Parson, A., \& Rhubart, D. (2014). The marcellus shale impacts study: Chronicling social and economic change in north central and southwest pennsylvania. harrisburg. The Center for Rural Pennsylvania. Retrieved from https://www.rural.palegislature.us/ documents/reports/The-Marcellus-Shale-Impacts-Study.pdf

Crawley, A., Beynon, M., \& Munday, M. (2013). Making location quotients more relevant as a policy aid in regional spatial analysis. Urban Studies, 50(9), 1854-1869.

Department of Statistics Malaysia. (2008). Malaysia standard industrial classification 2008. Putrajaya: Department of Statistics Malaysia.

Department of Statistics Malaysia. (2014). Input-output table Malaysia 2010. Putrajaya: Department of Statistics Malaysia.

Department of Statistics Malaysia. (2015a). National account gross domestic products by state. Putrajaya: Department of Statistics Malaysia.

Department of Statistics Malaysia. (2015b). The labour force survey report, Malaysia. Putrajaya: Department of Statistics Malaysia.

Department of Statistics Malaysia. (2017a). Economic census 2016: MyState statistics Sarawak. Putrajaya: Department of Statistics Malaysia.

Department of Statistics Malaysia. (2017b). National accounts gross domestic product by state. Putrajaya: Department of Statistics Malaysia.

Doraisami, A. (2015). Has Malaysia really escaped the resource curse? A closer look at the political economy of oil revenue management and expenditure. Resources Policy, 45, 98-108.

Dülger, F., Lopcu, K., Burgaç, A., \& Balli, E. (2013). Is Russia suffering from Dutch Disease? Cointegration with structural break. Resources Policy, 38(4), 605-612.

Economic Planning Unit. (2016). Eleventh Malaysia plan, 2016-2020. Putrajaya: Economic Planning Unit.

Faturay, F., Lenzen, M., \& Nugraha, K. (2017). A new sub-national multi-region input-output database for Indonesia. Economic System Research, 29(2), 234-251.

Gazi, M. N. I., Kusairi, M. N., Shaufique, F. S., \& Aswani Farhana, M. N. (2014). Economic impact of artificial reefs: A case study of small scale fishers in Terengganu, Peninsular Malaysia. Fisheries Research, 151, 122-129.

Gerelmaa, L., \& Kotani, K. (2016). Further investigation of natural resources and economic growth: do natural resources depress economic growth? Resources Policy, 50, 312-321.

Habibullah, M. S., \& Radam, A. (2009). Industry concentration in rich and poor states in Malaysia: Location quotient and shift share analysis. ICFAI Journal of Industrial Economics, 6(1), 56-65.

Haggerty, J., Gude, P. H., Delorey, M., \& Rasker, R. (2014). Long-term effects of income specialization in oil and gas extraction: The U.S. West, 1980-2011. Energy Economics, 45, $186-195$.

Hasanov, F. (2013). Dutch disease and the Azerbaijan economy. Communist and Post-Communist Studies, 46(4), 463-480.

Jamal, O., Mazrura, S., Mastura, M., \& Khadzir M. S. A. (2014). Transboundary smoke haze pollution in Malaysia: inpatient health impacts and economic valuation. Environmental Pollution, 189, 194-201.

James, A., \& Aadland, D. (2011). The curse of natural resources: An Empirical Investigation of U.S. Counties. Resource and Energy Economics, 33(2), 440-53.

Khalid, A. R., \& Liwan, A. (2012). Oil and gas trends and implications in Malaysia. Energy Policy, $50,262-271$. 
Krugman, P. (1987). The narrow moving band, the Dutch disease, and the competitive consequences of Mrs. Thatcher: Notes on trade in the presence of dynamic scale economies. Journal of Development Economics, 27(1-2), 41-55.

Lenzen, M. (2003). Environmentally important paths, linkages, and key sectors in the Australian economy. Structural Change and Economic Dynamics, 14(1), 1-34.

Lenzen, M., Geschke, A., Wiedmann, T., Lane, J., Anderson, N., Baynes, T., Boland, J., Daniels, P., Dey, C., Fry, J., Hadjikakou, M., Kenway, S., Malik, A., Moran, D., Murray, J., Nettleton, S., Poruschi, L., Reynolds, C., Rowley, H., Ugon, J., Webb, D., \& West, J. (2014). Compiling and using input-output frameworks through collaborative virtual laboratories. Science of the Total Environment, 485, 241-251.

Malaysian German Chamber of Commerce \& Industry. (2010). Market watch 2010: The timber sector in Malaysia. Retrieved from http://www.malaysia.ahk.de/fileadmin/ahk_malaysia/ Dokumente/Sektorreports/Market_Watch_2010/Timber_2010_ENG_.pdf

Maniloff, P., \& Mastromonaco, R. (2014). The local economic impacts of hydraulic fracturing and determinants of Dutch disease. (Working Paper No. 8). Retrieved from http://econbuspapers.mines.edu/working-papers/wp201408.pdf

Mayer, W., \& Pleeter, S. (1975). A theoretical justification for the use of location quotients. Regional Science and Urban Economics, 5(3), 343-355.

Miller, R. E., \& Blair, P. D. (2009). Input-output analysis: Foundations and extensions (2nd ed.). Cambridge: Cambridge University Press.

Morrissey, K. (2014). Producing regional production multipliers for Irish marine sector policy: A location quotient approach. Ocean \& Costal Management, 91, 58-64.

Munasib, A., \& Rickman, D. S. (2015). Regional economic impacts of the shale gas and tight oil boom: A synthetic control analysis. Regional Science and Urban Economics, 50, 1-17.

Norman, M. (2016). Malaysia's timber trade trends. Retrieved from https://www.foresttrends.org/wp-content/uploads/imported/malaysias-timber-trade-trends_marigoldnorman-forest-trends-pdf.pdf

Papyrakis, E., \& Gerlagh, R. (2007). Resource abundance and economic growth in the United States. European Economic Review, 51(4), 1011-1039.

Paredes, D., Komarek, T., \& Loveridge, S. (2015). Income and employment effects of shale gas extraction windfalls: Evidence from the Marcellus region. Energy Economics, 47, 112-120.

Park, S. Y., \& Yoo, S. H. (2014). The dynamics of oil consumption and economic growth in Malaysia. Energy Policy, 66, 218-223.

Rabiul, I., Chamhuri, S., Shaharuddin, M. I., Abdul, H. J., Kamal, U., \& Santhapparaj, A. S. (2010). Economic impacts of tropical timber sector in Malaysia. Australian Journal of Basic and Applied Sciences, 4(8), 3216-3223.

Richardson H. W. (1972). Input-output and regional economics. London: Weidenfeld \& Nicolson.

Round J. I. (1983). Non-survey techniques: A critical review of the theory and the evidence. International Regional Science Review, 8(3), 189-212.

Saari, M. Y. (2014). Input-output analysis: Foundations and applications for policy analysis in Malaysia. Kuala Lumpur: University Malaya Press.

Saari, M. Y., Dietzenbacher, E., \& Los, B. (2016). The impacts of petroleum price fluctuations on income distribution across ethnic groups in Malaysia. Ecological Economics, 130, 25-36.

Saari, M. Y., Habibullah, M. S., Utit, C., \& Maji, I. K. (2018). Economic impacts of petroleum industry in states of Pahang and Terengganu. Jurnal Ekonomi Malaysia, 52(2), 149-161. 
Shahwahid, H. O. (1992). Economic impact of Malaysian timber exports. Journal of Tropical Forest Science, 5(1), 54-67.

Solarin, S. A., \& Shahbaz, M. (2015). Natural gas consumption and economic growth: The role of foreign direct investment, capital formation and trade openness in Malaysia. Renewable and Sustainable Energy Reviews, 42, 835-845.

Solaymani, S., Kardooni, R., Kari, F., \& Sumiani, Y. (2014). Economic and environmental impacts of energy subsidy reform and oil price shock on the Malaysian transport sector. Travel Behaviour and Society, 2(2), 65-77.

Teh, L. S. L., Teh, L. C. L., \& Sumaila, U. R. (2011). Quantifying the overlooked socio-economic contribution of small-scale fisheries in Sabah, Malaysia. Fisheries Research, 110(3), 450 458.

Umachandran, K., \& Sawicka, B. (2017). Study of timber market of Malaysia and its impact on the economy and employment. Journal of Advances in Agriculture, 7(3), 1123-1130.

Weber, J. G. (2012). The effects of a natural gas boom on employment and income in Colorado, Texas, and Wyoming. Energy Economics, 34(5), 1580-1588.

World Bank. (2006). Where is the wealth of nations?: Measuring capital for the 21st century. Retrieved from http://documents.worldbank.org/curated/en/287171468323724180/ pdf/348550REVISED0101Official0use0ONLY1.pdf.

Zubaidah, H., Pakhriazad, H. Z., Hasmadi, I., \& Khairil, W. A. (2014, February). Trend of timber products export in Malaysia. Paper presented at the International Conference on Business, Management, and Corporate Social Responsibility, Batam. Retrieved from https://www.researchgate.net/profile/Zubaidah_Harun/publication/267402508_TREND OF_TIMBER_PRODUCTS_EXPORT_IN_MĀLAYSIA/links/544f43560cf2 $\overline{6} \mathrm{dda} 0890 \overline{2} \mathrm{~b}$ 06/TREND-OF-TIMBER-PRODUCTS-EXPORT-IN-MALAYSIA.pdf. 